\title{
El pensamiento utópico en Christa Wolf
}

María Belén Castano ${ }^{1}$

\section{Resumen:}

La propuesta se detiene en analizar el eco del pensamiento utópico de Ernst Bloch presente en los ensayos de Christa Wolf Der Schatten eines Traumes. Karoline von Günderrode -ein Entwurf (1978) y Nun ja! Das nächste Leben geht aber heute an. Ein Brief über die Bettine (1979). Asimismo, se profundizará la caracterización del romanticismo de Wolf como revolucionario utópico, que implica una crítica a la modernidad y a la civilización capitalista y que está ligado al feminismo.

Palabras clave: utopía; Christa Wolf; Bloch; romanticismo.

\section{The utopian component in Christa Wolf}

\begin{abstract}
:
This paper will analyze the echo of the utopian thought of Ernst Bloch present in the Christa Wolf's essays Der Schatten eines Traumes. Karoline von Günderrode -ein Entwurf (1978) and Nun ja! Das nächste Leben geht aber heute an. Ein Brief über die Bettine (1979). Likewise, we will focus in the characterization of Wolf's romanticism as utopian revolutionary, which implies a critique of Modernity and capitalist civilization and that is linked to feminism.
\end{abstract}

Keywords: Utopia; Christa Wolf; Bloch; Romanticism.

\section{Introducción}

Sayre y Löwy (1995, p. 104) caracterizan a Wolf como una escritora romántica ya sea por su fuerte interés por los escritores alemanes románticos sino también por su cosmovisión romántica Weltanschauung, que implica una crítica a la modernidad y a la civilización capitalista tecnológica que surge en el siglo dieciocho, inspirada en aquellos valores pre-modernos. Este aspecto que aparece en sus escritos tempranos, se vuelve central en Kein Ort. Nirgends y en los ensayos sobre Karoline von Günderrode y Bettine von Arnim, ya que

\footnotetext{
${ }_{1}^{1}$ Doutoranda em Literatura Alemã pela Universidad de Buenos Aires/Conicet. E-mail: belcastano@gmail.com.
} 
estas autoras románticas consideradas al margen del canon literario se pronunciaron en contra de las normas del patriarcado.

La propuesta se detiene en analizar el eco del pensamiento utópico de Ernst Bloch presente en los ensayos sobre Bettine Brentano y Karoline von Günderrode Der Schatten eines Traumes. Karoline von Günderrode -ein Entwurf (1978) y Nun ja! Das nächste Leben geht aber heute an. Ein Briefüber die Bettine (1979). Asimismo, se profundizará la caracterización del romanticismo de Wolf como revolucionario utópico y ligado al feminismo.

Si bien las reflexiones sobre el feminismo no son un tema representativo de la obra de Ernst Bloch nos ocuparemos de destacar la actualidad que tienen las consideraciones presentes en el ensayo Kampft uns neue Weib, Programm der Frauenbewegung presente en Das Prinzip Hoffnung (1954-9) en relación al elemento utópico con el que caracteriza los sueños de una nueva mujer que habían comenzado a surgir hacia principios de 1900 y cómo ellos se vinculan con lo expresado por las autoras románticas outsiders elegidas por Wolf.

Ernst Bloch fue profesor de filosofía en la Universidad de Leipzig desde 1949 a 1957, donde Christa Wolf realizó sus estudios y su influencia en la obra de la autora de Der geteilte Himmel ha sido poco indagada.

\section{El aspecto romántico revolucionario de Ernst Bloch y su caracterización de las utopías del movimiento feminista}

Löwy (2007, p. 14) señala que Bloch define a sus primeros escritos y en particular al Thomas Münzer como románticos revolucionarios y considera que esto se aplica al conjunto de su obra. Aclara que por "romanticismo" no entiende solamente una escuela literaria de comienzos del siglo XIX, sino una vasta corriente cultural de protesta, en nombre de ciertos valores sociales o culturales del pasado, contra la civilización capitalista moderna en tanto sistema de racionalidad cuantificadora y de desencantamiento del mundo (2007, pp. 14ss). En oposición al romanticismo conservador o reaccionario que aspira a la restauración de los privilegios y jerarquías del antiguo régimen, el romanticismo revolucionario integra las conquistas de 1789 y en lugar de plantear "un retorno a lo anterior, se funda en un rodeo por el pasado comunitario (2007, p. 15). Löwy indica que Bloch siempre permaneció fiel a sus intuiciones juveniles y no renegó jamás del romanticismo revolucionario de sus primeros escritos y que es posible encontrar en Das Prinzip Hoffnung frecuentes referencias a Geist der Utopie, en particular a la idea de utopía como conciencia anticipadora, como figura de "pre-apariencia" (2007, pp. 15; 16).

Ureña Pastor (1986, pp. 242ss) analiza el sesgo utópico con el que Bloch caracteriza al hombre y explora su deseo de zambullirse en las utopías abstractas del pasado para captar los sueños de una vida mejor vividos por el 
hombre occidental de antaño. También, destaca la relevancia de la actitud de protesta que revelan las utopías abstractas al orden establecido y que manifiestan una tensión que implica una ruptura hacia un mundo distinto del presente (1986, pp. 242ss). Son cinco los grupos de las utopías del pasado que Bloch investiga en su análisis histórico que se enfoca en las ilusiones de la salud, de una sociedad sin miseria y en los milagros de la técnica: las utopías médicas [die ärtzlichen Utopien]; las utopías sociales [Sozialutopien]; las utopías técnicas [technische Utopien]; las utopías arquitectónicas [architektonische Utopien] y las utopías geográficas [geographische Utopien]. En su estudio, Bloch se detiene también en las utopías contemporáneas a su época: el movimiento juvenil [Jugendbewegung]; el movimiento feminista [Frauenbewegung] y el movimiento judío, conocido con el nombre de sionismo (1986, p. 271). Con respecto a las mujeres, Bloch rastrea el origen del movimiento feminista a fines del siglo XIX a partir de la utopía forjada por ese grupo basada en las ansias de reivindicación de la mujer, recluida en la casa, con la obligación de servir y agradar, reducida a la pasividad, que sueña con una mujer nueva, libre de toda enajenación y discriminación (BLOCH, 2006, p. 163).

La mujer está abajo: desde hace tiempo está organizada para ello. La mujer está siempre a mano, siempre presta a ser utilizada; es la más débil y siempre está atada a la casa. En la vida de la mujer se hallan estrechamente unidos el servir y la obligación de agradar, porque el hecho de agradar hace también estar al servicio. La joven tenía que ser sustentada por el matrimonio, y así tenía que permanecer a la espera, tenía que aguardar al marido. (BLOCH, 2006, p. 163)

El planteo de Bloch incluye un reconocimiento de los avances que se emprenden a principios del siglo XX, por parte de mujeres, cuyos sueños -de no ser oprimidas- considera sugestivos y actuales (BLOCH, 2006, p. 163). Sin embargo, critica las limitaciones de dichas conquistas en la sociedad capitalista, al considerar que el capital, al darle un lugar a las profesiones de la mujer, había estado interesado en eliminar todo lo que sonara a libertad y a verdadera emancipación socialista:

la joven burguesa se hizo responsable de ganarse el sustento, pero ello la hizo independiente solo en apariencia. En lugar del derecho al amor libremente escogido, en lugar de la vida libre, lo que vino fue la monotonía de la oficina y, además, en la mayoría de los casos, en una posición subordinada (BLOCH, 2006, p. 164).

Más aún, Bloch subraya cómo la inserción laboral de la mujer se había articulado en puestos mal pagos, para una subalternidad voluntaria, al compás de una objetivación capitalista que había premiado una innegable sobriedad de la mujer (BLOCH, 2006, p. 167). Y sostiene que "el movimiento feminista es suficiente para crear una utopía parcial, tal como la ha creado ya en las utopías generales precedentes" y considera que "este elemento propuesto y 
esperado llevará también en la sociedad sin clases a la deliberación y a la acción, como un problema propio heredado" (BLOCH, 2006, p. 171). Asímismo, plantea Bloch que solo en una sociedad socialista, libre de explotación económica y social, podrá la mujer desarrollar las posibilidades latentes de su femeneidad:

La emancipación femenina de especie concreta apunta, en cambio, a ejemplos auténticos desde la perspectiva utópico esencial. (...) Y ello tanto más seguramente cuanto que en una sociedad sin clases desaparecen las múltiples y alienadas categorías de mercancía y de dominación que, sobre todo en el capitalismo, han contribuido a moderlar los tipos de mujer aparecidos hasta ahora. (BLOCH, 2006, p. 172)

Bloch considera que lo utópico en la mujer, allí dónde aparece previamente como valioso [vorerscheint] "muestra un aspecto de profundidad humana central y consoladora (BLOCH, 2006, p. 173).

\section{Las huellas de la utopía de Bloch en Bettine Brentano y Karoline von Günderrode}

Algunos antecedentes que rastrean la influencia de Bloch en la obra de Wolf, se pueden encontrar en el estudio de Huyssen (1979), que plantea el componente utópico presente en su novela más conocida Nachdenken über Christa T. (1968). Para Huyssen, es posible advertir que la protagonista, Christa T., encarna la esperanza superadora de la alienación en la sociedad socialista: "La esperanza de que surja la utopía como un medio para eliminar la alienación"2 (HUYSSEN, 1979, p. 83).

Consideramos que las figuras femeninas del romanticismo alemán que Wolf pone a la luz, Bettine von Arnim y Karoline Günderrode, se identifican con una intención utópica que encuentra coincidencias con el estudio de Bloch mencionado. La utopía de estas figuras, muy poco usual para la época, está ligada a el sueño de un mundo en el que las mujeres dejen de estar excluidas, oprimidas y relegadas al espacio doméstico y en el que su voz y su escritura puedan ser consideras. Wolf reflexiona también sobre el vínculo entre la poesía y la utopía que se desprende de las epístolas de estas autoras.

En los años 70 se asiste a un redescubrimiento del romanticismo entre los escritores de la RDA y es en esta época que Wolf se concentra principalmente en trabajar dos temas: el período del romanticismo temprano en Alemania y el lugar que las mujeres habían tenido o dejado de tener en la sociedad desde entonces (MCPHERSON, 1988, p. XVIII). El centro de su interés lo ocuparon las figuras de Bettine Brentano y Karoline von Günderrode

${ }^{2}$ La traducción es mía. 
(1780-1806), hija mayor huerfána de una familia aristocrática que tuvo que vivir en un convento de mujeres y que formó lazos con distintos miembros del círculo de los Románticos de Heidelberg a principios del siglo XIX; entre ellos con Bettine Brentano (1785 -1859), hermana del poeta Clemens y más adelante esposa del poeta Achim von Arnim. De Bettine en particular Wolf declara admirar su modo directo de decir las cosas, su coraje que mostró en la vida en general y su activismo político feminista en Berlín. La amistad entre las dos mujeres fue documentada en la novela epistolar Die Günderrode publicada en 1839 por Bettine Brentano. Wolf rescata la protesta de Anna Seghers en el intercambio epistolar que tuvo en 1938-9 con Lukács, al señalar que Günderrode había sido excluída del canon literario por él considerado junto con otras figuras outsiders de los inicios del siglo XIX como Büchner, Kleist y Hölderin. En la carta del 28 de junio de 1938, Seghers le recuerda a Lukács que Goethe se había pronunciado muy desvaforablemente a propósito de una generación de escritores con su confrontación categórica en la que asocia el clacisismo con lo saludable y el romanticismo con la enfermedad (LUKÁCS, 1971, p. 345) y menciona la manera fría con la que acogió a Kleist y a muchos otros. Vedda encuentra similitudes entre la preferencia de la autora de Das siebte Kreuz por autores envueltos en los conflictos de la época, que habían manifestado agitación y consternación por su época, en oposición al concepto de obra orgánica y cerrada como expresión de acomodamiento del statu quo (2010, p. 127). Y sostiene que la capacidad de Wolf, de representar una realidad desgarrada se corresponde con una representación del ser humano entero que "no implica ver al hombre como entidad armónica; a contrapelo de la literatura y la estética del clasicismo alemán, Wolf concibe al hombre como una entidad múltiple y paradójica", con la convicción de que "la misión de la literatura es poner de manifiesto esa diversidad conflictiva, sin recubrir las contradicciones bajo una 'bella apariencia' estética” (VEDDA, 2010, p. 127).

El ensayo Der Schatten eines Traumes. Karoline von Günderrode -ein Entwurf, sobre Karoline Von Günderrode, fue publicado en 1978. Nos interesa resaltar cómo el mismo da cuenta de una denuncia implícita al patriarcado, inusual para la época.

Kuhn (1988, pp. 149ss) sostiene que en dicho estudio Wolf caracteriza a los personajes cómo víctimas de una transición histórica y señala que en este ensayo es posible identificar el concepto de Ungleichzeitigket de Ernst Bloch.

McPherson (1988, p. xix) sostiene que en la lectura de Wolf, tal como indica el título del poema de Günderrode que es también el de este trabajo, se arraiga en la visión de que la vida de Günderrode estaba ubicadas en los márgenes de la sociedad, una vida en la sombra de un sueño.

Se destaca el hecho que este ensayo plantea una serie de lamentos por parte de Günderrode ligados a su género: al no haber nacido hombre, señala la dificultad de querer escribir siendo mujer. Su autorrealización a través de la 
escritura la tuvo que hacer utilizando el pseudónimo masculino "Tian" con el que publicó poesía, obras y prosa y, como era costumbre en aquella época, escribió muchas cartas. Wolf hace alusión a la incongruencia de la época [die Unstimmgkeit der Zeit] que experimenta Günderrode a los veintiún años y sostiene que había sido marcada por un dilema insoluble, con una vida corta, pobre en acontecimientos pero rica en conmociones interiores (WOLF, 1990, p. 511). Al quitarse la vida, deja una obra corta en gran parte ignorada que es redescubierta un siglo después, ya que la novela de Bettine Brentano La Günderrode (1840) no había logrado mantener vivo su recuerdo.

Wolf sostiene que no es casual que sean justamente las mujeres las que cuestionen y retraten los males de la época, ya que al no tener trabajos ni independencia económica no tenían nada que perder al decir lo que pensaban; ella encuentra una curiosa contradicción: el surgimiento de un pensamiento libre y utópico al que denomina la "religión de lo inestable" [Schwebereligion] en un contexto de total dependencia del género (WOLF, 1990, p. 542). Esta religión se basa, para Wolf en la no admisión de una educación acabada, que permita a cada uno descubrirse a sí mismo. Esto se refiere a la sed de conocimiento y a la búsqueda de la autenticidad, algo que permea, a su vez, toda la obra de Wolf.

Wolf pone a la luz aquí las dificultades que atraviesa Günderrode por ser mujer, por haber nacido en el seno de una familia aristocrática empobrecida cuyo padre había muerto prematuramente y cuya madre, por la que ella no se sabe amada, es incapaz de ofrecerle un hogar a sus hijos; Karoline ayuda a su hermana a huir de la casa materna y a otra la cuida muy joven en su lecho de muerte.

La autora subraya la escapatoria que encuentra Günderrode en el trabajo intelectual. Al mismo tiempo, introduce la denuncia sobre la falta de lugar para las mujeres de dicha época en áreas como la política, la producción y el comercio y cómo eso generaba en ellas un sentimiento de inferioridad y la experimentación de una pérdida de la realidad.

Se advierte cómo el ensayo hace hincapié en la desdicha del género masculino durante el proceso de industrialización temprana, que lleva a los hombres a la renuncia de sí mismos y a la división de sí mismos; y ello, para Wolf, había afectado su capacidad de amar y los había obligado a rechazar a las mujeres más libres (WOLF, 1990, p. 549). Al mismo tiempo, Wolf considera que en dicha coincidencia histórica las mujeres empiezan a escribir y a mostrar su verdadera forma de ser (WOLF, 1990, p. 549). Sostiene que en el romanticismo muchas callan y se convierten en amas de casa virtuosas y algunas, muy pocas, comienzan a escribir: es allí cuando marca el comienzo de la literatura femenina. Asimismo, sostiene que este tipo de mujeres van a convertirse en las grandes ciudades en las fundadoras de los salones y ve en el tono de sus confesiones, en sus intereses y opiniones un intento, tal vez 
inconsciente, de introducir elementos femeninos en la cultura estructurada sobre el patriarcado (WOLF, 1990, p. 541).

Wolf identifica una visión revolucionaria en estas primeras intelectuales femeninas y analiza la manera particular en la que viven los inicios de la era industrial, de la división del trabajo y de la alabanza a la ratio entendida, para ellas como violación de la naturaleza.

Resulta sugestiva la reflexión en la que Wolf sostiene que la poesía tiene algo en común con la esencia de la utopía, al decir que tiende a la búsqueda impaciente y espontánea del absoluto (WOLF, 1990, p. 570). Sin embargo, considera que la mayoría de las personas no puede soportar que se exprese en voz alta el malestar ante la insuficiencia y las limitaciones de la vida a las que han de resignarse (WOLF, 1990, p. 570). Wolf hace hincapié en el carácter de outsider de Günderrode que termina con su vida y que no puede adaptarse al mundo de las convenciones, de una sociedad que pretende medirlo todo en cantidad, con la radical división del trabajo; en ese contexto hostil pone a los poetas en el lugar de víctimas de los demás y de sí mismos (WOLF, 1990, p. 571).

El ensayo sobre Bettine ${ }^{3}$ von Arnim Nun ja! Das nächste Leben geht aber heute an. Ein Brief über die Bettine (1979), fue publicado un año después que el de Günderrode. Reúne detalles biográficos de su vida y constituye un documento valioso de denuncia del patriarcado de la época.

Wolf explora en detalle la trayectoria de vida e intelectual de esta figura. El texto adquiere el formato de una carta en la que la autora presenta detalles sobre su vida a un interlocutor denominado D. Menciona su deseo de abordar temas similares a los que Bettine von Arnim trata en su novela epistolar Die Günderrode y destaca que la distancia histórica le brinda una ventaja de perspectiva. Sostiene que las cartas sobre las que Bettine había basado su libro en 1839 habían sido escritas en 1804 y 1806: el encuentro con Karoline Günderrode se da en la época en la que Bettine aún no tenía veinte años, en la casa de su abuela, la famosa escritora Sophia La Roche (WOLF, 1990, p. 572). Karoline era cinco años menor que Bettine y en seguida se apegó a ella, la visitaba a diario en su cuarto en el convento de Frankfurt am Main, le leía en voz al alta, anotaba sus poemas, planeaba viajes y compartía muchas cuestiones con ella. Wolf menciona que Bettine se sentía sola en el ambiente rico de los Brentano y su hermano Clemens se la presenta a Achim von Arnim como una joven ingeniosa, que no sabe que lo es y que se siente infeliz con su familia.

3 Cabe destacar que Wolf replica la variabilidad del nombre Bettine a veces escrito con "a" y otras con "e". 
Con respecto a las denuncias del patriarcado, en primer lugar Wolf cuenta que la familia le reprocha a la joven Bettine por estudiar hebreo en lugar de cultivar las virtudes domésticas que un esposo podría apreciar.

En segundo lugar, Wolf destaca las diferencias entre Bettine y Günderrode. La primera se prometía a sí misma no ser infeliz y aceptaba la vida que le tocaba. Günderrode se sentía condicionada por los códigos burgueses de vida y se sometía a los códigos burgueses del arte en la poesía.

En tercer lugar, Wolf presenta una reflexión sobre la forma de este ensayo que considera particular para la época y representativa de una voluntad por parte de las mujeres de resistencia a la dominación de un cierto tipo de forma de canon: un canon a las que ambas se sometieron al mismo tiempo, standard para su trabajo. En este estudio, Wolf profundiza la correspondencia entre Bettine y Günderrode, de la que destaca el carácter poético, el lenguaje ditirámbico, el tono muchas veces efusivo, la intemperancia. También considera que la forma que adopta este texto es un híbrido: algo que, como mencionamos antes, se vincula con la resistencia a la dominación al canon de la época. Wolf sostiene que especialmente para Günderrode tratar de estar cerca del canon establecido para la época era necesario para poder ser considera una poeta significativa (WOLF, 1990, p. 601). La autora de Nachdenken über Christa T. describe el particular vínculo de amor que las une, marcado por la admiración de Bettine por la filosofía femenina de Günderrode y (WOLF, 1990, p. 603), cuyo camino es opuesto al de la autoaniquilación de la cultura masculina agresiva. En cuarto lugar, Wolf sostiene que el de Günderrode y Bettine se trata de un vínculo muy particular, cuyo ejemplo en la literatura es quizás el único, un vínculo que es alternativo al masculino.

\section{El interés de Wolf por el romanticismo}

En la entrevista con Frauke Meyer Goasau, que fue publicada por primera vez en Berlín Oriental en Alternative (1982), Wolf detalla algunas cuestiones que nos permiten profundizar nuestra reflexión sobre el carácter utópico y el romanticismo revolucionario de los ensayos analizados. Wolf admite que, más allá del interés personal por las biografías de estas autoras, lo que a ella le interesaba más a la hora de ocuparse del romanticismo era indagar cuándo había comenzado la feroz división entre los individuos y la sociedad. Es por ello que se pregunta hasta qué punto la división del trabajo cobró un protagonismo tal que la literatura había sido expulsada de la sociedad y su comprensión dejó de ser esencial para entender la realidad. Al mismo tiempo, considera que en esta misma época el elemento femenino también había sido expulsado de la sociedad, aunque esto había comenzado mucho antes. La autora observa que en esta etapa de incipiente sociedad industrial, tanto 
mujeres como intelectuales habían tenido cada vez menos influencia en los procesos determinantes de las vidas de la esfera social y que la severidad de esta transformación habría llevado a ambos a un lugar de outsider (WOLF, 1990, p. 880).

Wolf declara que no se había interesado tanto por el concepto de Romanticismo como movimiento y no considera a Günderrode como un personaje romántico en sentido estricto (WOLF, 1990, p. 880). Lo que a ella le interesa explorar es la incapacidad de algunos autores de esta generación para cooperar con su tiempo, con su talento, con la literatura y con su vida personal; quienes en términos burgueses pero también para la teoría literaria marxista fracasan [scheitern] ((WOLF, 1990, p. 881). Wolf confiesa que gracias a Seghers había conocido por primera vez el nombre Günderrode y luego había comenzado su investigación sobre ella. Lo que más le interesa a Wolf de los románticos es la experiencia de vida que transmiten, su vida en grupos, en los márgenes de la sociedad: aquellas figuras literarias centrales que, estaban en los bordes de la sociedad burguesa. Asimismo, se interesa por el modo en el que las mujeres del romanticismo inician ese proceso, al ser las que más tenían la necesidad de expresarse a través de los márgenes. Con este nuevo interés de Wolf por el romanticismo, a diferencia de lo que había estudiado sobre literatura alemana, descubre el componente de los románticos de experimento social protagonizado por un pequeño grupo de personas progresistas.

\section{Conclusiones}

Nos propusimos indagar elaboración ficcional que realiza Wolf de las trayectorias de vida de las poetas del romanticismo temprano con el fin de, por un lado, dar cuenta de su vínculo con el aspecto revolucionario utópico del movimiento romántico que exploran Sayre y Löwy (1995), afín a una crítica a la modernidad y a la civilización capitalista que nos permite evidenciar la potencia de los reclamos del feminismo que los ensayos de Wolf sobre Günderrode y Bettine Brentano traslucen. Por otro lado, exploramos la relación que estos ensayos tienen con las imágenes utópicas de emancipación femenina que Bloch propone en Das Prinzip Hoffnung. Al indagar el proceso histórico de los sueños de liberación del movimiento feminista a fines del siglo XIX, Bloch plantea que solo en una sociedad socialista, libre de explotación económica y social, podrá la mujer desarrollar las posibilidades latentes de su feminidad (BLOCH, 2006, p. 172).

Para Bloch "el mundo se encuentra pleno de disposiciones, tendencias y latencias que apuntan a algo, y ese algo es la realización de la intención utópica: un mundo liberado de sufrimientos indignos, de angustia, de alienación" (LÖWY, 2007, p. 16). En este sentido, es que identificamos en 
estos ensayos de Wolf la intención utópica que radica en el abordaje de las trayectorias de vida de estas mujeres del romanticismo, que considera en los márgenes de la sociedad de su época y que anhelan un mundo libre de alienación y con igualdad de oportunidades entre los géneros. Esto se relaciona, también, con la reflexión, antes mencionada, que realiza Wolf sobre la escritura, y las primeras mujeres de la época, como Günderrode, que empiezan a escribir y que marcan el vínculo entre la poesía y la utopía.

Wolf considera que los románticos forman parte de una de las generaciones que habían sentido que la potencia de sus intensas inquietudes, deseos, pasiones que fluían en sus conversaciones y círculos literarios no podía traducirse en acción. Advierte que esto es difícil en las sociedades industriales orientadas hacia la eficiencia y la producción masiva y que esto se convierte en un fenómeno marginal. Wolf destaca que son las mujeres justamente las que inician ese proceso, al ser las que más tenían la necesidad de expresarse a través de los márgenes, en contra de los modos totalitarios y restrictivos de la sociedad. En segundo lugar, el foco de Wolf en estas autoras se puede interpretar como una defensa de la postura de Seghers que retoma estas figuras poniéndolas por encima de los clásicos en su debate epistolar con Lukács. Al recuperar la voz de estas mujeres, al mismo tiempo, Wolf realiza una crítica implícita al patriarcado, fundamentada en el desplazamiento del canon literario de estas figuras femeninas y pone en un lugar central a estas mujeres como precursoras de la literatura femenina. En tercer lugar, Wolf a través de estos ensayos da cuenta de las dificultades de las mujeres que se reunían en los grupos de Heidelberg y denuncia la compleja situación de Karoline von Günderrode y de Bettine Brentano. La primera obligada a vivir en un convento sin ninguna posibilidad de tener independencia sobre su vida, al no estar casada no podía tener ningún rol en la vida pública ni tener una profesión para vivir. En cambio sostiene que Bettine Brentano había padecido la situación opuesta: después de casarse con el poeta Achim von Arnim tuvo siete hijos, y se sintió oprimida por los cuidados domésticos y familiares; luego de la muerte de su marido se convirtió en activista de los derechos de la mujer. La publicación de las obras de Günderrode, aunque sea con un pseudónimo fue, para Wolf, el único triunfo que ella había podido tener, ya que la escritura, le había podido permitir trascender la banalidad de las restricciones de su tiempo, (WOLF, 1990, p. 888).

La intención de explorar el vínculo entre el carácter romántico revolucionario que presentan Wolf y Bloch a la hora de esbozar escenarios utópicos -en los que la mujer no sea considerada un objeto- va de la mano del anhelo, que ambos comparten de una emancipación del género humano, en una sociedad libre de explotación y humillaciones. 


\section{Referências bibliográficas}

BLOCH, Ernst. Kampft uns neue Weib, Programm der Frauenbewegung. En: Das Prinzip Hoffnung: in 5 Teilen. Kapitel 32-42, Frankfurt Am Main: Surkamp, 1993, pp. 687-98.

. La lucha por la nueva mujer: programa del movimiento feminista. En: El principio esperanza v. 2. Edición al cuidado de Francisco Serra. Trad. Felipe González Vicén. Madrid: Trotta, 2006, pp. 163-73.

HUYSSEN, Andreas. Auf den Spuren Ernst Blochs. En: SAUER, Klaus (Ed.). Christa Wolf. Materialienbuch. Darmstad und Neuwied: Hermann Luchterhand Verlag GmbH \& Co. KG, 1979, pp. 81-7.

KUHN, Anna K. Christa Wolf's utopian vision from Marxism to feminism. Cambridge: Cambridge University Press, 1988.

LÖWY, Michael. Utopía y romanticismo revolucionario en Ernst Bloch. En: VEDDA, Miguel (Comp.). Ernst Bloch. Tendencias y latencias de un pensamiento. Buenos Aires: Herramienta, 2007.

; SAYRE, Robert. Romanticism as a feminist vision: the quest of Christa Wolf. New German Critique, n. 64, 1995, pp. 105-34.

LUKÁCS, György. Ein Briefwechsel zwischen Anna Seghers und Georg Lukács (1938/39). En: Werke. Essays über Realismus. Neuwied y Berlín: Luchterhand, 1971, pp. 345-68.

MCPHERSON, Karin. Christa Wolf - an introduction. En: The fourth dimension: interviews with Christa Wolf. Trad. Pilkington Hilary. Bristol: Verso, 1988.

MEYER-GOSAU, Frauke. Lebensform Prosa. Eine Wegbeschreibung von der Moskauer Novelle zu Was bleibt.: Text + Kritik, n. 46, 1994, pp. 23-32.

UREÑA PASTOR, Manuel. Ernst Bloch. ¿Un futuro sin Dios? Madrid: Biblioteca de Autores Cristianos de la Editorial Católica, 1986.

VEDDA, Miguel. La dimensión crítica del autor. Christa Wolf como ensayista. En: JANÉ, Jordi; SIGUÁN, Marisa (Ed.). Was bleibt? Christa Wolf y los temas literarios de la reunificación alemana. Barcelona: Sociedad Goethe de España, 2010, pp. 119-29.

WOLF, Christa. Der Schatten eines Traumes. Karoline von Günderrode -ein Entwurf". En: Christa Wolf. Die Dimension des Autors. Essays und Aufsätze Reden und Gespräche 1959-1985 Band 2. [1987]. Darmstadt: Sammlung Luchterhand, 1990a, pp. 511-71.

. Nun ja! Das nächste Leben geht aber heute an. Ein Brief über die Bettine. En: Christa Wolf. Die Dimension des Autors. Essays und Aufsätze Reden und Gespräche 1959-1985 Band 2. [1987]. Darmstadt: Sammlung Luchterhand, 1990b, pp. 572-610.

Die Dimension des Autors. Essays und Aufsätze Reden und Gespräche 1959-1985 Band 2. [1987]. Darmstadt: Sammlung Luchterhand, 
1990c.

. Die Dimension des Autors. Essays und Aufsätze Reden und Gespräche 1959-1985 Band 1 [1987]. Darmstadt: Sammlung Luchterhand, 1990c.

Como citar:

CASTANO, María Belén. El pensamiento utópico en Christa Wolf. Verinotio Revista on-line de Filosofia e Ciências Humanas, Rio das Ostras, v. 26, n. 1, pp. 216-27, jan./jun. 2020.

Data do envio: 14 mar. 2020

Data do aceite: 6 maio 2020 